\title{
What do we know about COVID-19 Vaccines for Children?
}

Reese H. Clark, MD, Veeral N. Tolia, MD, Curtis B. Pickert, MD

\section{Introduction}

Our goal is to review the current literature on the safety and efficacy of COVID-19 vaccines in children, some of which will be out of date before the end of the month. There is still much to be learned about vaccines to prevent COVID-19 in children.

The accumulating data in adults is encouraging. Authorized mRNA vaccines are highly effective in preventing SARS-CoV-2 infection and severe disease when administered in real-world conditions. Vaccines attenuated the viral RNA load, risk of febrile symptoms, and duration of illness among those who had breakthrough infection despite vaccination. (1)

"The accumulating data in adults is encouraging. Authorized mRNA vaccines are highly effective in preventing SARSCoV-2 infection and severe disease when administered in real-world conditions. Vaccines attenuated the viral RNA load, risk of febrile symptoms, and duration of illness among those who had breakthrough infection despite vaccination. (1)"

\section{Why are safe, effective vaccines for children needed?}

1. Protect children from acute infections with COVID-19 and reduce the risk of Multisystem Inflammatory Syndrome in children (MIS-C).

2. Facilitate in-person learning and socialization and promote mental health support for recovery from the ill effects of social isolation.

3. Contribute to herd immunity.

4. Improve access to all forms of care. Shelter-in-place orders have been associated with declines in outpatient pediatric visits and fewer vaccine doses administered, leaving chil-

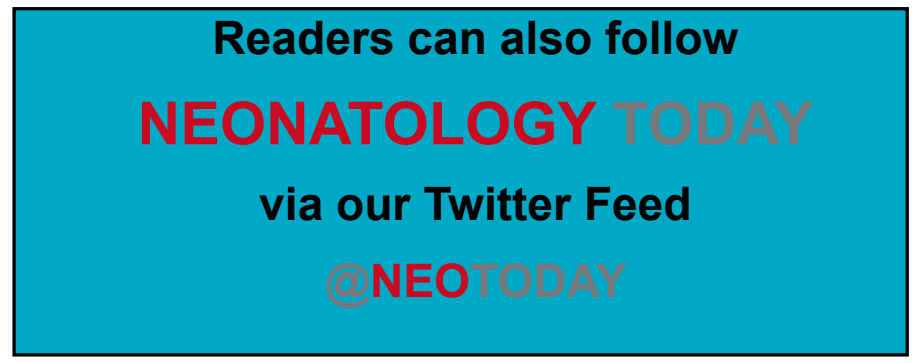

dren at risk for vaccine-preventable diseases. Establishing herd immunity can improve access to all forms of care (spiritual, mental, health, and physical) and all vaccines.

\section{What is known}

1. There are at least two distinctively different COVID-related diseases in children: an acute illness that is similar, but not the same, as that seen in adults, and MIS-C. There is also increasing evidence that children can have persistent symptoms (Long COVID) following testing positive for COVID-19.

2. While it is rare, children can become critically ill and die with COVID-19.

3. Vaccines elicit an immune response to the components that make up the vaccine, and the immune response is different in children than in adults.

4. The BNT162b2 (Pfizer-BioNTech) vaccine in adolescents between 12 to 15 years was at least $75 \%$ (lower $95 \%$ confidence limit) effective in preventing Covid-19 cases with an onset of 7 or more days after dose 2. Currently, this is the only vaccine with FDA emergency authorization for children.

5. Common adverse events (e.g., local injection reactions, headache, fatigue, muscle aches, and fever) resolve without treatment and are not serious.

\section{What is not known}

1. Duration of protection for any vaccine in any age group

2. The immune response to COVID-19 is different in children; it will be important to understand that to define the pathophysiology of MIS-C.

3. How well do vaccines prevent people from spreading COVID-19 to others?

4. How effective vaccines are for preventing new variants of the virus that causes COVID-19.

5. Why states chose different ways to define the term "child," variable definitions created different denominators in reported rates, creating confusion when rates of disease or adverse events in "children" are reported. Children population cohorts are variably defined as $<18$ years old or $<21$ years old.

6. What rare serious adverse events are truly related to vaccination and when to anticipate their occurrence in relation to receiving the vaccine (first vs. the second dose).

7. How the Delta Variant of SARS-CoV-2 changes the risk of infectivity, long and short-term disease in children?

8. Nothing in medicine is 100 percent safe and effective. Never say "always works" or "never hurts." Our job as clinicians is to weigh the risks and benefits, often without perfect knowledge of efficacy or safety.

Context/prevalence/incidence/severity of disease in children There are two distinctively different COVID-related diseases in 
children; an acute illness that is similar, but not the same, as that seen in adults, and MIS-C. CDC defines children as under 21 years old. The incubation period for acute infection with SARSCoV-2 in children is 2-14 days with an average of 6 days. The signs and symptoms of acute COVID-19 in children are like influenza, streptococcal pharyngitis, and allergic rhinitis. The lack of specificity of signs or symptoms and the significant proportion of asymptomatic infections make symptom-based screening for identification of SARS-CoV-2 in children particularly challenging. (2)

\section{"The lack of specificity of signs or symptoms and the significant proportion of asymptomatic infections make symptom-based screening for identification of SARS-CoV-2 in children particularly challenging. (2)"}

In "Children and COVID-19: State-Level Data Report," the definition of a "child" case is based on varying ages $(0-14,0-17,0-18$, $0-19$, and 0-20 years) reported across different states. Summary data from the AAP report shows that of children tested, $5 \%-35 \%$ test positive for COVID-19. As of September 2, 5 million children have tested positive for COVID-19. There were 251,781 cases added $8 / 26 / 21-9 / 2 / 21$, five times the number of cases reported during weeks in July. Children now represent $15.1 \%$ of all COVID-19 cases reported since the beginning of the pandemic. From $8 / 12 / 21-8 / 19 / 21$, children represented $22.4 \%(180,175 / 806,003)$ of the weekly reported cases. 251,781 child COVID-19 cases were reported the past week from 8/26/21-9/2/21, and children represented $26.8 \%(251,781 / 939,470)$ of the weekly reported cases. (3) COVID-19-associated hospitalization rates among children and adolescents rose nearly five-fold from late June to mid-August 2021. (4)

When infected, children generally remain asymptomatic or develop mild disease. Between 0.2 and 1.9 percent of children with COVID-19 require hospitalization, and 1 in 3 children hospitalized with COVID-19 in the United States are admitted to the intensive care unit. (1) Mortality in children with critical disease has been reported to be $3.8 \%$. $(5,6)$

The CDC reports 412 COVID-related deaths in children 0-17 years old in 2020 and 2021 through September 2, 2021. (7) Child deaths due to COVID-19 are rare and generally occur in children with comorbidities. The most common reported comorbidities are chronic lung disease (including asthma), cardiovascular disease, and immune suppression. In studies from the United States, an underlying medical condition was noted in $77 \%$ of hospitalized children, in contrast with $12 \%$ of those not hospitalized. (8)

Since mid-May 2020, the CDC has tracked case reports of MIS-C (children $<21$ years old), a rare but serious condition associated with COVID-19. As of August 27, 2021, there were 4661 total cases of MIS-C and 41 deaths in children meeting the case definition. (9) The median age of patients with MIS-C is nine years. Half of the children with MIS-C are between the ages of 5 and 13 years. Sixty-two percent of the reported patients with race/ethnicity infor- mation available occurred in Hispanic children or Latino $(n=1,280)$ or Black, Non-Hispanic ( $n=1,077$ cases). Ninety-nine percent of patients had a positive test result for SARS CoV-2. The remaining $1 \%$ of patients had contact with someone with COVID-19. Sixty percent of reported patients were male. (9)

Of 394 PICU patients with Coronavirus Disease, $171(43.4 \%)$ had MIS-C. Children with MIS-C were more likely younger (2-12 years vs adolescents; $p<0.01)$, Black $(35.6 \%$ vs $21.9 \%$; $p<0.01)$, more likely to present with fever/abdominal pain than cough/dyspnea ( $p$ $<0.01$ ), and less likely to have comorbidities $(33.3 \%$ vs $61.9 \%$; $p$ $<0.01)$ compared with those without MIS-C. Inflammatory marker levels, use of inotropes/vasopressors, corticosteroids, and anticoagulants were higher in MIS-C $(p<0.01)$. Overall mortality was $3.8 \%(15 / 394)$, with no difference in the two groups. Diagnosis of MIS-C in children was associated with a longer duration of hospitalization as compared to non-MIS-C in children (7.5 d [interquartile range, 5-11] vs. $5.3 d$ [interquartile range, $3-11 d$ ]; $p<0.01$ ). (5)

There are emerging reports of long COVID-19 in children. Symptoms range from cough and shortness of breath to fatigue, headache, palpitations, chest pain, joint pain, physical limitations, depression, and insomnia. Data from the United Kingdom Coronavirus Infection Survey found that $13 \%$ of children under the age of 11 and $15 \%$ of children ages 12 to 16 years continued to have at least one symptom five weeks after testing positive for $\mathrm{CO}$ VID-19. (10)

\section{"During the pandemic, parents with children ages 5-12 reported their children showed elevated symptoms of depression (4\%), anxiety (6\%), and psychological stress (9\%); and experienced overall worsened mental or emotional health (22\%)."}

\section{Mental health impact of impact on children}

During the pandemic, parents with children ages 5-12 reported their children showed elevated symptoms of depression $(4 \%)$, anxiety $(6 \%)$, and psychological stress (9\%); and experienced overall worsened mental or emotional health (22\%). More than $25 \%$ of high school students reported worsening emotional and cognitive health, and over $20 \%$ of parents with children ages 5-12 reported similar worsening conditions for their children. (11)

\section{Relevant data with respect to the population of children in- cluded in the BNT162b2 (Pfizer-BioNTech) trial}

"BNT162b2 (Pfizer-BioNTech) is a Covid-19 vaccine containing nucleoside-modified messenger RNA encoding the severe acute respiratory syndrome coronavirus 2 (SARS-CoV-2) spike glycoprotein. In healthy adults, two $30-\mu \mathrm{g}$ doses of BNT162b2 elicited high neutralizing titers and robust, antigen-specific CD4+ and CD8+ T-cell responses against SARS-CoV-2. In phase 2-3 part of an ongoing global clinical trial in people 16 years of age or 
older, BNT162b2 had a favorable safety profile characterized by transient mild-to-moderate injection-site pain, fatigue, and headache and was 95\% effective in preventing Covid-19 from 7 days after dose 2. Based on these findings, BNT162b2 received emergency use authorization from the Food and Drug Administration (FDA) on December 11, 2020, for Covid-19 prevention in persons 16 years of age or older. On May 10, 2021, the emergency use authorization was expanded to include persons 12 years of age or older based on data reported to the FDA."- $(12,13)$ On August 23 , 2021, the FDA approved the first COVID-19 vaccine. The PfizerBioNTech COVID-19 Vaccine is approved to prevent COVID-19 disease in individuals 16 years of age and older. The vaccine also continues to be available under emergency use authorization (EUA), including for individuals 12 through 15 years of age and for the administration of a third dose in certain immunocompromised individuals. (14)

\section{FDA Evaluation of Effectiveness Data}

The effectiveness data to support the EUA in adolescents down to 12 years of age is based on immunogenicity and analysis of COVID-19 cases. The immune response to the vaccine in 190 participants, 12 through 15 years of age, was compared to the immune response of 170 participants, 16 through 25 years of age. (13) The immune response (based on Serum Neutralization Assay) was greater in adolescents than in young adults.

An analysis of cases of COVID-19 occurring among participants, 12 through 15 years of age, seven days after the second dose was also conducted. In this analysis, among participants without evidence of prior infection with SARS-CoV-2, no cases of COVID-19 occurred among 1,005 vaccine recipients, and $16(1.6 \%)$ cases of COVID-19 occurred among 978 placebo recipients; the vaccine was $100 \%$ effective in preventing COVID-19. (12)- The observed vaccine efficacy was $100 \%(95 \% \mathrm{Cl}, 75.3$ to 100$)$. There are limited data to address whether the vaccine can prevent transmission of the virus from person to person. At this time, data are not available to determine how long the vaccine will provide protection.

FDA Evaluation of Available Safety Data in Adolescence 1215 (13)

Phase $1 / 2 / 3$ of the Pfizer-BioNTech COVID-19 Vaccine trials have enrolled approximately 46,000 participants, including 2,260 participants 12 through 15 years of age. Of 2,260, 1,131 adolescent participants received the vaccine, and 1,129 received a saline placebo. More than half of the participants were followed for safety for at least two months following the second dose.

Adverse events in children 12-15 years of age.

Common side effects in the adolescent clinical trial participants were pain at the injection site, tiredness, headache, chills, muscle pain, fever, and joint pain. Symptoms typically lasted 1-3 days. More adolescents reported side effects after the second dose than after the first dose.

Serious Adverse Events (SAEs) in children 12-15 years of age.

The frequency of SAEs was low among all participants; five serious adverse events (0.4\%) were reported among vaccine recipients and two (0.2\%) among placebo recipients, with no statistically significant difference in frequency observed between the two groups. None of the SAEs were considered related to the vaccine.

\section{Ongoing Safety Monitoring}

Pfizer Inc. and vaccination providers must report the following to the Vaccine Adverse Event Reporting System for Pfizer-BioNTech COVID-19 Vaccine: all vaccine administration errors, serious adverse events, cases of MIS-C, and cases of COVID-19 that result in hospitalization or death.

\section{"As of July 16, 2021, approximately 8.9 million US adolescents aged 12-17 years had received the Pfizer-BioNTech COVID-19 vaccine."}

As of July 16, 2021, approximately 8.9 million US adolescents aged 12-17 years had received the Pfizer-BioNTech COVID-19 vaccine.

Summary of population-based methods for identifying adverse events in children who are eligible to receive a vaccine (15)

There are two reporting systems.

1. Vaccine Adverse Event Reporting System (VAERS) is a passive vaccine safety surveillance system comanaged by CDC and FDA that monitors adverse events after vaccination. Under COVID-19 vaccine emergency use authorization requirements, health care providers must report certain adverse events after vaccination to VAERS, including death. VAERS reports are classified as serious if any of the following are reported: hospitalization or prolongation of hospitalization, lifethreatening illness, permanent disability, congenital anomaly or birth defect, or death. Reports of serious adverse events receive follow-up to obtain additional information, including medical records; for reports of death, death certificates and autopsy reports are obtained, if available. $\underline{C D C}$ physicians reviewed available information for each decedent to form an impression about the cause of death.

2. $\quad$-Safe. The CDC established V-Safe, a voluntary smartphone-based active safety surveillance system, to monitor adverse events after COVID-19 vaccination. Adolescents who receive a COVID-19 vaccine are eligible to enroll in VSafe, through self-enrollment or as a dependent of a parent or guardian and receive scheduled text reminders about online health surveys. Health surveys sent in the first week after vaccination include questions about local injection sites, systemic reactions, and health impacts. If a report indicated medical attention was sought, VAERS staff members contacted the reporter and encouraged completion of a VAERS report, if indicated.

\section{VAERS data summary adolescents aged 12-17 years (15)}

VAERS received and processed 9,246 reports of adverse events for adolescents aged 12-17 years who received the Pfizer-BioNTech vaccine from December 14, 2020-July 16, 2021. Overall, $8,383(90.7 \%)$ VAERS reports were for non-serious events, and $863(9.3 \%)$ for serious events. Among the 863 serious conditions and diagnostic findings, the common reports were chest pain $487 / 863(56.4 \%)$, increased troponin levels 360/863 (41.7\%), 
myocarditis $348 / 863(40.3 \%)$, and increased c-reactive protein 264/863 (30.6\%). (15)

CDC reviewed 14 reports of death after vaccination. Among the decedents, four were aged 12-15 years, and ten were aged 1617 years. CDC physicians reviewed all death reports; impressions regarding the cause of death were pulmonary embolism (two), suicide (two), intracranial hemorrhage (two), heart failure (one), hemophagocytic lymphohistiocytosis and disseminated Mycobacterium chelonae infection (one), and unknown or pending further records (six). No reports of death to VAERS were determined to be the result of myocarditis. Two cases of severe myocarditis have been reported in adults. (16)

\section{Limitation of VAERS}

VAERS is a passive surveillance system and is subject to underreporting and reporting biases. Data in VAERS is not validated. The precise percent of the 8.9 million US adolescents aged 12-17 years who received the Pfizer-BioNTech vaccine and subsequently had an SAE cannot be known because research quality data on each patient who receives a vaccine is not captured. The denominator used in the tables is not all vaccinated patients; instead, it is the 9,246 adolescents with adverse events who were reported to VAERS. The data reported above only describe the characteristics and demographics of events. (14)

V-Safe data summary adolescents aged 12-17 years (15)

“During December 14, 2020-July 16, 2021, V-Safe enrolled 66,350 adolescents aged $16-17$ years who received the PfizerBioNTech vaccine." (15) After the Pfizer-BioNTech vaccine was authorized for adolescents aged 12-15 years (beginning May 10, 2021), V-Safe enrolled 62,709 adolescents in this age group. Less than $1 \%$ of adolescents aged $12-17$ years required medical care in the week after receiving either dose; 56 adolescents $(0.04 \%)$ were hospitalized.

\section{"The Vaccine Adverse Event Reporting System (VAERS) had received 1226 $(0.000038 \%)$ preliminary reports of myocarditis and pericarditis after about 300 million doses of the Pfizer and Moderna vaccines up to June 11, 2021. There were $233(0.006427 \%)$ cases of myocarditis or pericarditis after 3,625,574 second doses administered to men aged 18-24."}

\section{Limitation of V-Safe}

Approximately 129,000 US adolescents aged $12-17$ years voluntarily enrolled in V-Safe after Pfizer-BioNTech vaccination. Voluntary reporting may represent a selected population who are willing to report health care data on themselves. Therefore, V-Safe data might not be generalizable to the overall vaccinated adolescent population. Rates of adverse events could be over-reported. It is reassuring that the CDC V-Safe reported local (63.4\%) and sys- temic $(48.9 \%)$ reactions with a frequency similar to that reported in preauthorization clinical trials.

\section{Adult and teen myocarditis/pericarditis reports}

The Vaccine Adverse Event Reporting System (VAERS) had received $1226(0.000038 \%)$ preliminary reports of myocarditis and pericarditis after about 300 million doses of the Pfizer and Moderna vaccines up to June 11,2021 . There were $233(0.006427 \%)$ cases of myocarditis or pericarditis after 3,625,574 second doses administered to men aged 18-24. Based on population cohort studies, 2 to 25 cases would have been expected. After 5,237,262 doses administered to women in this age group, $27(0.000516 \%)$ cases were reported; 2 to 18 would have been predicted. A similar pattern of risk was seen in children 12-17 years old. (17) The crude reporting rates of myocarditis or pericarditis decreased with increasing age as did the gender differences.

In Israel, $275(0.0055 \%)$ cases of myocarditis were reported between December 2020 and May 2021 among more than five million vaccinated people. Most of the cases were in men aged 1619 , usually after the second dose. In most cases, myocarditis took the form of a mild illness that lasted a few days. (18)

The United States military administered more than 2.8 million doses of mRNA COVID-19 between January 1 and April 30, 2021. Twenty-three male military members patients (median [range] age, 25 [20-51] years) presented with marked chest pain within four days after receipt of an mRNA COVID-19 vaccine. All were previously healthy and physically fit. Seven received the BNT162b2-mRNA vaccine (Pfizer-BioNTech), and 16 received the mRNA-1273 vaccine (Moderna). Twenty patients had symptom onset following the second dose. Testing did not identify other etiologies for myocarditis, including acute COVID-19, infections, ischemic injury, or underlying autoimmune conditions. All patients received brief supportive care and were recovered or recovering at the time of this report. While the number of myocarditis cases was small, the number was higher than expected among male military members. (19)

Joint statement on vaccines and myocarditis or pericarditis. (20) -

An exceedingly small number of people will experience myocarditis or pericarditis after vaccination. Importantly, most cases are mild for the young people who do, and individuals often recover independently or with minimal treatment. Myocarditis and pericarditis are more common if one gets COVID-19, and the risks to the heart from COVID-19 infection can be more severe.

\section{Adult data on other serious adverse events}

Anaphylaxis after COVID-19 vaccination is rare and occurred in approximately 2 to 5 people per million vaccinated in the United States based on events reported to VAERS. (21) This kind of allergic reaction almost always occurs within 30 minutes after vaccination.

Safety monitoring of the J\&J/Janssen vaccine suggests a rare risk of a serious adverse event called "thrombosis with thrombocytopenia syndrome (TTS)," which may be associated with the $\mathrm{J} \& \mathrm{~J} / \mathrm{J}$ anssen vaccine. Most reports of this serious condition have been in adult women younger than 50 years old. It is estimated that one person in 318,750 vaccinated people is at risk for this disease.

"As of June 30, 2021, approximately 141 million second mRNA 
COVID-19 vaccine doses had been administered in the United States to persons aged $\geq 18$ years. Within VAERS, 497 reports of myocarditis after the second mRNA COVID-19 vaccine dose were received for persons aged $\geq 18$ years. The reporting rate of myocarditis overall among adults was 3.5 cases per million second doses of mRNA COVID-19 vaccine administered. In subgroup analyses by age and sex, the reported rate was highest among males aged $18-29$ years (24.3 cases per million mRNA COVID-19 vaccine second doses administered). (22)"-

\section{CDC conclusion $(23,24)$}

The Advisory Committee on Immunization Practices conducted a risk-benefit assessment and continues to recommend the PfizerBioNTech COVID-19 vaccine for all persons aged $\geq 12$ years.

\section{AAP recommendations (25)}

The AAP recommends COVID-19 vaccination for all children and adolescents 12 years of age and older who do not have contraindications using a COVID-19 vaccine authorized for use for their age.

After full approval of the Pfizer-BioNTech COVID-19 vaccine, the $A A P$ released a statement strongly discouraging the off-label use of this vaccine in children 11 years old and younger. Clinical trials for the COVID-19 vaccine in children ages 11 years old and younger are actively enrolling patients to evaluate the safety and efficacy of the COVID-19 vaccine in this age group. $(26,27)$

\section{"As of June 11, 2021, the FDA endorsed only the Pfizer-BioNTech vaccine for emergency use in 12- to 17-year-olds. Moderna applied Thursday, June 10, 2021, for authorization for its shot in adolescents aged 12 to 15 . No vaccine is authorized or approved for younger children."}

\section{Vaccines available as of August 23, 2021}

As of June 11, 2021, the FDA endorsed only the Pfizer-BioNTech vaccine for emergency use in 12- to 17-year-olds. Moderna applied Thursday, June 10, 2021, for authorization for its shot in adolescents aged 12 to 15 . No vaccine is authorized or approved for younger children.

All linked websites were last accessed on September 11, 2021.

\section{References:}

1. Thompson MG, Burgess JL, Naleway AL, Tyner H, Yoon SK, Meece J, Olsho LEW, Caban-Martinez AJ, Fowlkes AL, Lutrick K, Groom HC, Dunnigan K, Odean MJ, Hegmann K, Stefanski E, Edwards LJ, Schaefer-Solle N, Grant L, Ellingson K, Kuntz JL, Zunie T, Thiese MS, Ivacic L, Wesley MG, Mayo Lamberte J, Sun X, Smith ME, Phillips AL, Groover KD, Yoo YM, Gerald J, Brown RT, Herring MK, Joseph G, Beitel S, Morrill TC, Mak J, Rivers P, Poe BP, Lynch B, Zhou Y, Zhang $J$, Kelleher A, Li Y, Dickerson M, Hanson E, Guenther K, Tong S, Bateman A, Reisdorf E, Barnes J, Azziz-Baumgartner E,
Hunt DR, Arvay ML, Kutty P, Fry AM, Gaglani M. Prevention and Attenuation of Covid-19 with the BNT162b2 and mRNA1273 Vaccines. N Engl J Med. 2021 July 22;385(4):320-329. doi: 10.1056/NEJMoa2107058. Epub 2021 June 30. PMID: 34192428; PMCID: PMC8262622.

2. https://www.cdc.gov/coronavirus/2019-ncov/hcp/pediatrichcp.html (accessed 9/11/2021)

3. https://www.aap.org/en/pages/2019-novel-coronaviruscovid-19-infections/children-and-covid-19-state-level-datareport (accessed 9/11/2021)

4. Delahoy MJ, Ujamaa D, Whitaker M, O'Halloran A, Anglin O, Burns E, Cummings $C$, Holstein R, Kambhampati AK, Milucky J, Patel K, Pham H, Taylor CA, Chai SJ, Reingold A, Alden NB, Kawasaki B, Meek J, Yousey-Hindes K, Anderson EJ, Openo KP, Teno K, Weigel A, Kim S, Leegwater L, Bye E, Como-Sabetti K, Ropp S, Rudin D, Muse A, Spina N, Bennett NM, Popham K, Billing LM, Shiltz E, Sutton M, Thomas A, Schaffner W, Talbot HK, Crossland MT, McCaffrey K, Hall AJ, Fry AM, McMorrow M, Reed C, Garg S, Havers FP; COVID-NET Surveillance Team; COVID-NET Surveillance Team. Hospitalizations Associated with COVID-19 Among Children and Adolescents - COVID-NET, 14 States, March 1, 2020-August 14, 2021. MMWR Morb Mortal Wkly Rep. 2021 September 10;70(36):1255-1260. doi: 10.15585/ mmwr.mm7036e2. PMID: 34499627.

5. Tripathi S, Gist KM, Bjornstad EC, Kashyap R, Boman K, Chiotos K, Gharpure VP, Dapul H, Sayed IA, Kuehne J, Heneghan JA, Gupta M, Khandhar PB, Menon S, Gupta N, Kumar VK, Retford L, Zimmerman J, Bhalala US; Society of Critical Care Medicine Discovery Viral Infection and Respiratory IIIness Universal Study (VIRUS): COVID-19 Registry Investigator Group. Coronavirus Disease 2019-Associated PICU Admissions: A Report from the Society of Critical Care Medicine Discovery Network Viral Infection and Respiratory IIIness Universal Study Registry. Pediatr Crit Care Med. 2021 Jul 1;22(7):603-615. doi: 10.1097/PCC.0000000000002760. PMID: 33965987; PMCID: PMC8240492.

6. Lorenzo VB, Nascimento-Carvalho CM. Differences between children with severe acute lower respiratory infection with or without SARS-Cov-2 infection. J Infect. 2021 Aug;83(2):e1-e3. doi: 10.1016/j.jinf.2021.05.038. Epub 2021 June 12. PMID: 34090916; PMCID: PMC8197553.

7. https://www.cdc.gov/nchs/nvss/vsrr/covid weekly/index. htm\#SexAndAge (accessed 9/11/2021)

8. Tsabouri S, Makis A, Kosmeri C, Siomou E. Risk Factors for Severity in Children with Coronavirus Disease 2019: A Comprehensive Literature Review. Pediatr Clin North Am. 2021 Feb;68(1):321-338. doi: 10.1016/j.pcl.2020.07.014. Epub 2020 July 30. PMID: 33228941; PMCID: PMC7392074.

9. https://covid.cdc.gov/covid-data-tracker/\#mis-national-surveillance (accessed 9/11/2021)

10. NewsCAP: Growing concern about the risk of 'long COVID' in children., AJN, American Journal of Nursing: June 2021 - Volume 121 - Issue 6 - p 15 doi: 10.1097/01.NAJ.0000753612.88791.f5

11. https://www.kff.org/coronavirus-covid-19/issue-brief/mentalhealth-and-substance-use-considerations-among-childrenduring-the-covid-19-pandemic/ (accessed 9/11/2021)

12. https://www.fda.gov/news-events/press-announcements/ coronavirus-covid-19-update-fda-authorizes-pfizer-biontechcovid-19-vaccine-emergency-use (accessed 9/11/2021)

13. Frenck RW Jr, Klein NP, Kitchin N, Gurtman A, Absalon 
J, Lockhart S, Perez JL, Walter EB, Senders S, Bailey R, Swanson KA, Ma H, Xu X, Koury K, Kalina WV, Cooper D, Jennings T, Brandon DM, Thomas SJ, Türeci Ö, Tresnan $D B$, Mather S, Dormitzer PR, Şahin U, Jansen KU, Gruber WC; C4591001 Clinical Trial Group. Safety, Immunogenicity, and Efficacy of the BNT162b2 Covid-19 Vaccine in Adolescents. N Engl J Med. 2021 July 15;385(3):239-250. doi: 10.1056/NEJMoa2107456. Epub 2021 May 27. PMID: 34043894; PMCID: PMC8174030.

14. https://www.fda.gov/news-events/press-announcements/ fda-approves-first-covid-19-vaccine (accessed 9/11/2021)

15. Hause AM, Gee J, Baggs J, et al. COVID-19 Vaccine Safety in Adolescents Aged 12-17 Years - United States, December 14, 2020-July 16, 2021. MMWR Morb Mortal Wkly Rep 2021;70:1053-1058. DOI: http://dx.doi.org/10.15585/mmwr. mm7031e1external icon.

16. Verma AK, Lavine KJ, Lin CY. Myocarditis after Covid-19 mRNA Vaccination. N Engl J Med. 2021 Aug 18:NEJMc2109975. doi: 10.1056/NEJMc2109975. Epub ahead of print. PMID: 34407340; PMCID: PMC8385564.

17. https://www.cdc.gov/vaccines/acip/meetings/downloads/slides2021-06/03-COVID-Shimabukuro-508.pdf (accessed 9/11/2021)

18. https://www.gov.il/en/departments/news/01062021-03 (accessed 9/11/2021)

19. Montgomery J, Ryan M, Engler R, Hoffman D, McClenathan $B$, Collins L, Loran D, Hrncir D, Herring K, Platzer M, Adams N, Sanou A, Cooper LT Jr. Myocarditis Following Immunization With mRNA COVID-19 Vaccines in Members of the US Military. JAMA Cardiol. 2021 Jun 29:e212833. doi: 10.1001/jamacardio.2021.2833. Epub ahead of print. PMID: 34185045; PMCID: PMC8243257.

20. https://www.hhs.gov/about/news/2021/06/23/statement-following-cdc-acip-meeting-nations-leading-doctors-nurses-publichealth-leaders-benefits-vaccination.html (accessed 9/11/2021)

21. Shimabukuro T. Allergic reactions including anaphylaxis after receipt of the first dose of Pfizer-BioNTech COVID-19 vaccine - United States, December 14-23, 2020. Am J Transplant. 2021 Mar;21(3):1332-1337. doi: 10.1111/ajt.16516. PMID: 33641264; PMCID: PMC8013489.

22. Rosenblum HG, Hadler SC, Moulia D, Shimabukuro TT, Su JR, Tepper NK, Ess KC, Woo EJ, Mba-Jonas A, Alimchandani M, Nair N, Klein NP, Hanson KE, Markowitz LE, Wharton M, McNally VV, Romero JR, Talbot HK, Lee GM, Daley MF, Mbaeyi SA, Oliver SE. Use of COVID-19 Vaccines After Reports of Adverse Events Among Adult Recipients of Janssen (Johnson \& Johnson) and mRNA COVID-19 Vaccines (Pfizer-BioNTech and Moderna): Update from the Advisory Committee on Immunization Practices - United States, July 2021. MMWR Morb Mortal Wkly Rep. 2021 August 13;70(32):1094-1099. doi: 10.15585/mmwr.mm7032e4. PMID: 34383735; PMCID: PMC8360272.

23. Rosenblum HG, Hadler SC, Moulia D, Shimabukuro TT, Su JR, Tepper NK, Ess KC, Woo EJ, Mba-Jonas A, Alimchan- dani M, Nair N, Klein NP, Hanson KE, Markowitz LE, Wharton M, McNally VV, Romero JR, Talbot HK, Lee GM, Daley MF, Mbaeyi SA, Oliver SE. Use of COVID-19 Vaccines After Reports of Adverse Events Among Adult Recipients of Janssen (Johnson \& Johnson) and mRNA COVID-19 Vaccines (Pfizer-BioNTech and Moderna): Update from the Advisory Committee on Immunization Practices - United States, July 2021. MMWR Morb Mortal Wkly Rep. 2021 August 13;70(32):1094-1099. doi: 10.15585/mmwr.mm7032e4. PMID: 34383735; PMCID: PMC8360272.

24. https://www.cdc.gov/coronavirus/2019-ncov/vaccines/recommendations/adolescents.html (accessed 9/11/2021)

25. Committee on Infectious Diseases. COVID-19 Vaccines in Children and Adolescents. Pediatrics. 2021 Aug;148(2):e2021052336. doi: 10.1542/peds.2021-052336. Epub 2021 May 12. PMID: 33980697.

26. https://www.aap.org/en/news-room/news-releases/ aap/2021/american-academy-of-pediatrics-cautionsagainst-off-label-use-of-covid-19-vaccines-in-children-under-12/ (accessed 9/11/2021)

27. https://clinicaltrials.gov/ct2/results?cond=covid-19+vaccines \&term $=$ \&type $=I n t r \& r s / t=\& r e c r s=a \& a g e \quad v=\& a g e=0 \& g n d r=\& h$ Ith $=Y$ \&intr $=$ \&titles $=$ \&outc $=\&$ spons $=$ \&lead $=$ \&id $=$ \&cntry $=U S \&$ state $=\& c i t y=\& d i s t=\& l o c n=\& r s u b=\& s t r d s=\& s t r d \quad e=\& p r c d$ $s=$ \&prcd e=\&sfpd $s=\& s f p d \quad e=\& r f p d \quad s=\& r f p d \quad e=\& l u p d$ $\underline{s=\text { \&lupd } e=\& \text { sort }=}$

Funding Source: None.

Financial Disclosure: The authors have indicated they have no financial relationships relevant to this article to disclose.

Conflict of Interest: The authors have indicated they have no potential conflict of interest relevant to this article to disclose.

\section{NT}

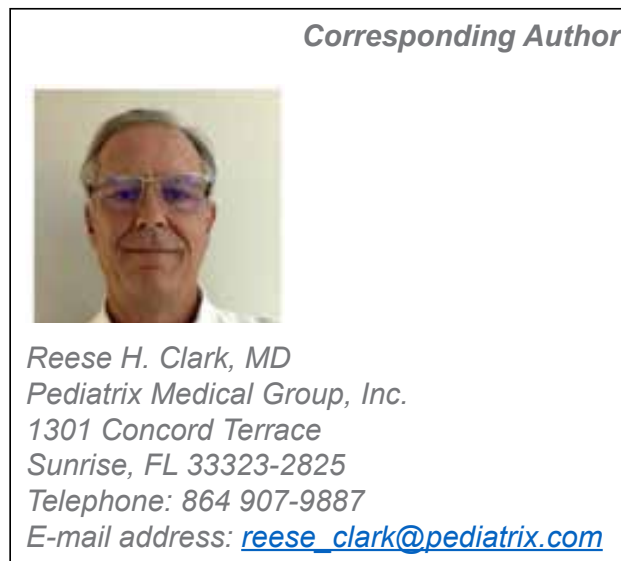

NEONATOLOGY TODAY is interested in publishing manuscripts from Neonatologists, Fellows, NNPs and those involved in caring for neonates on case studies, research results, hospital news, meeting announcements, and other pertinent topics. Please submit your manuscript to: LomaLindaPublishingCompany@gmail.com 


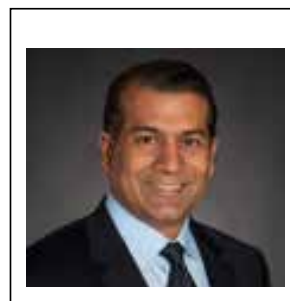

Veeral N. Tolia, MD

Pediatrix Medical Group, Inc.

1301 Concord Terrace

Sunrise, FL 33323-2825

Department of Neonatology,

Baylor University Medical Center and Pediatrix Medical Group,

Dallas, TX.

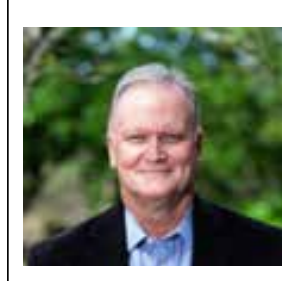

Curtis B. Pickert, MD

Pediatrix Medical Group, Inc.

1301 Concord Terrace

Sunrise, FL 33323-2825
Babies are just tiny adults, ight? So ... half?

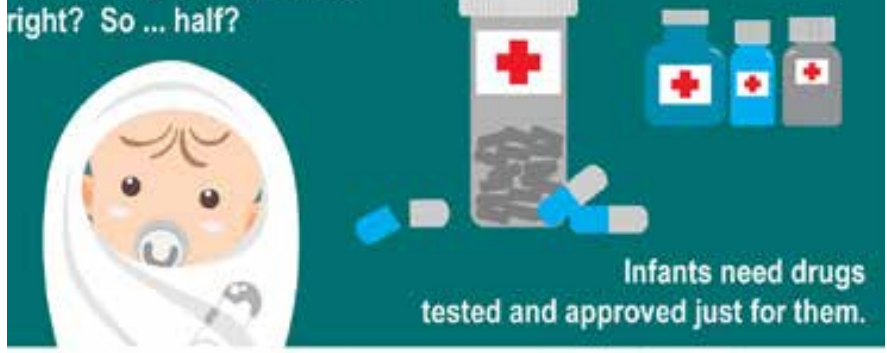

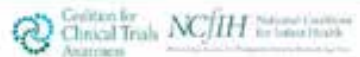

\section{NATIONAL PERINATAL ASSOCIATION}

\section{CORONAVIRUS}

\section{COVID-19}

\section{RELIABLE}

RESOURCES:

- CDC: 2019 Novel Coronavirus

- The Lancet: CoviD-19 and pregnancy

- MotherToBaby: Coronaviruses

- WHO: Emerging respiratory viruses

STAY INFORMED.

O National Perinatal

\section{www.nationalperinatal.org}

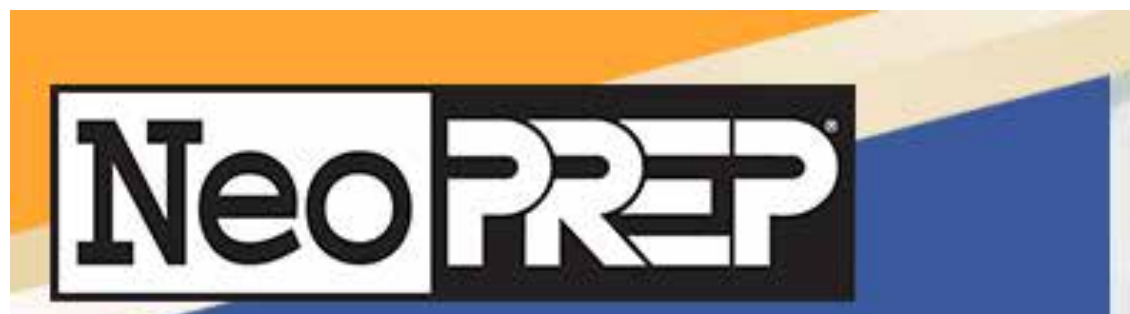

\section{An Intensive Review and Update of Neonatal-PerinatalMedicine}

\section{January 22-26, 2022}

San Antonio, TX

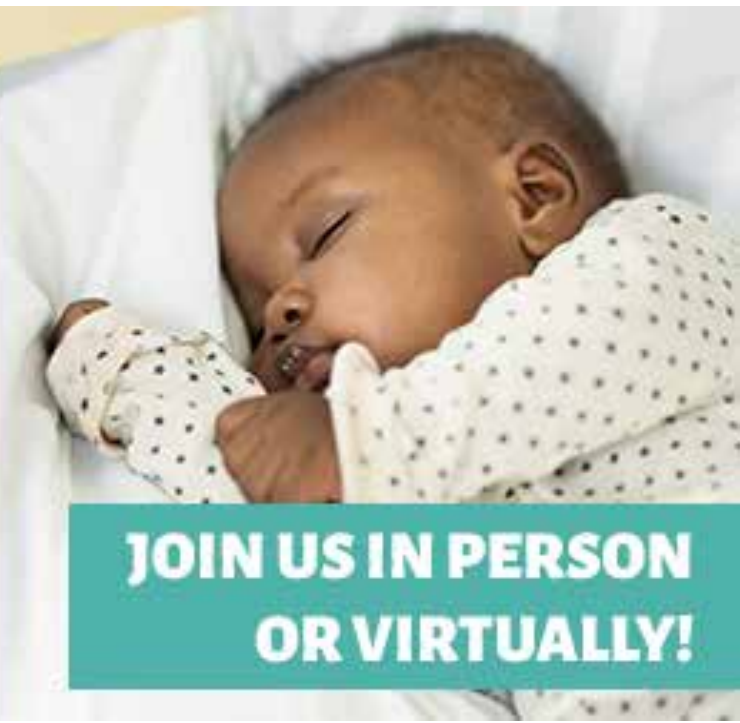

